\title{
Micronucleus test in peripheral blood of rats treated with hyperbaric oxygen after subtotal splenectomy preserving the lower pole ${ }^{1}$
}

\author{
Marcela Souza Lima PauloI, Ingryd Fortes Souza ${ }^{\mathrm{II}}$, Kethleen Gomes Wandekoken ${ }^{\mathrm{III}}$, Karina Balestreiro Silva ${ }^{\mathrm{IV}}$, Jean Carlos

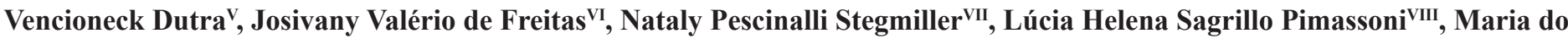 \\ Carmo Pimentel Batitucci ${ }^{\mathrm{IX}}$, Danilo Nagib Salomão Paulo ${ }^{\mathrm{x}}$, Flávia Imbroisi Valle Errera ${ }^{\mathrm{XI}}$
}

DOI: http://dx.doi.org/10.1590/S0102-865020150040000005

IFellow PhD degree=, Postgraduate Program in Surgical and Ophthalmological Applied Sciences, Federal University of Minas Gerais (UFMG), Belo Horizonte-MG, Brazil. Intellectual and scientific content of the study, acquisition and interpretation of data, manuscript preparation.

II Graduate student, School of Pharmacy, EMESCAM. Grant from Institutional Program for Scientific Initiation (PIBIC) of the National Council of Scientific and Technological Development (CNPq), Ministry of Science, Technology and Inovation, College of Health Sciences, Vitoria-ES, Brazil. Micronucleus procedures, analysis of data.

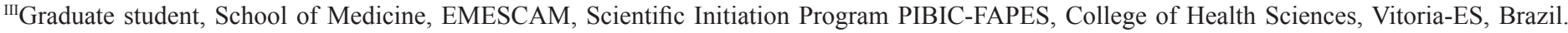
Technical procedures, acquisition of data.

${ }^{I V}$ Graduate student, School of Medicine, Scientific Initiation Program PIBIC-FAPES, College of Health Sciences, EMESCAM, Vitoria-ES, Brazil. Interpretation of data, manuscript writing.

${ }^{\mathrm{v} F e l l o w}$ Master degree, Postgraduate Program in Biotechnology, Espirito Santo Federal University (UFES), Vitoria-ES, Brazil. Micronucleus test technical validation.

${ }^{\mathrm{VI}}$ Fellow PhD degree, Postgraduate Program in Biotechnology, UFES, Vitoria-ES, Brazil. Technical procedures, interpretation of data.

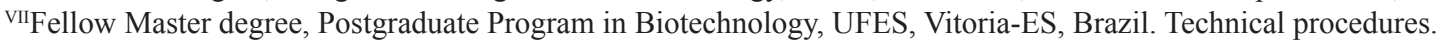

VIII Assistant Professor of Statistical, ICALP Research Center, College of Health Sciences, EMESCAM, Vitoria-ES, Brazil. Statistical analysis.

${ }^{\mathrm{IX}}$ Associate Professor of Genetics, Department of Biological Science, UFES, Vitoria-ES, Brazil. Conception of the study, micronucleus protocol, critical revision.

${ }^{\mathrm{x}} \mathrm{PhD}$, Chairman, Full Professor of Surgery, ICALP Research Center, College of Health Sciences, EMESCAM, Vitoria-ES, Brazil. Conception and design of the study, technical procedures, critical revision.

${ }^{\mathrm{XI} A s s o c i a t e}$ Professor of Genetics, ICALP Research Center, College of Health Sciences, EMESCAM, Vitoria-ES, Brazil. Intellectual and scientific content of the study, manuscript preparation.

\section{ABSTRACT}

PURPOSE: To assess the mutagenic potential of the oxygen inhalation therapy (HBO), by means of the micronucleus test, performed in peripheral blood of rats that underwent subtotal splenectomy with lower pole preservation (ESTPI), after HBO sessions or simulations. METHODS: Eighteen male Wistar rats, were distributed into three groups of six animals: group 1 - submitted to ESTPI and HBO sessions; group 2 - submitted to ESTPI and HBO simulations; group 3 - underwent cyclophosphamide administration. In groups 1 and 2, blood samples from the animals' tails were collected before surgery (T0) and immediately after the 13th HBO session or simulation (T1). In group 3, tail blood samples were collected from animals before (T0) and 24 hours after (T1) cyclophosphamide (CP) delivery. The number of micronucleated normochromatic erythrocytes (MNNCE) was determined by blind counting 2000 normochromatic erythrocytes (NCE) per animal.

RESULTS: Micronuclei average after CP delivery in group 3 was higher than before its use, thus confirming the mutagenic activity of this drug $(\mathrm{p}=0.01)$. In groups 1 and 2, no significant difference in the average of Micronuclei was observed when comparing it to blood samples before and after the 13th HBO session or simulation.

CONCLUSION: The treatment protocol used in this study did not induce Micronucleus formation in animals submitted to ESTPI and HBO treatment or simulation.

Key words: Splenectomy. Mutagenicity Tests. Oxygen Inhalation Therapy. Rats. 


\section{Introduction}

Hyperbaric oxygen therapy (HBO) is the exposure to oxygen inside a chamber under high pressure. The therapy aims at increasing the concentration of gas free fraction, which, when is not linked to haemoglobin and dissolved in plasma, reaches several body tissues. The protocol usually indicates the use of two absolute atmospheres of pressure, in sessions that last about 60 minutes. The therapy is indicated for several situations, including decompression sickness, acute carbon monoxide poisoning, air embolism, soft tissue infections and in treating delayed healing wounds ${ }^{1}$

Recently, other benefits from HBO were observed in experimental conditions. HBO treatment of the rats submitted to subtotal splenectomy with lower pole preservation (ESTPI) enabled the improvements in the lipid function and in the viability of the lower pole when compared with rats not submitted to $\mathrm{HBO}^{2}$, as well as the increase in cellular and vascular proliferation ${ }^{3,4}$. For the other hand, HBO has side effects such as pulmonary and neurologic toxicities, auditory barotrauma, discomfort in facial sinuses and temporary visual impairment. Such effects might be related to variations in the pressure and/or to the toxicity of oxygen, which in turn depends on its concentration when delivered during $\mathrm{HBO}^{5}$.

The exposure to high concentrations of oxygen leads to increases on the number of free radicals and reactive metabolites, which might be the responsible for the toxic effects from therapy, since several reactive oxygen species might act directly in the $\mathrm{DNA}^{6}$. As the occurrence of mutations might be related to carcinogenic events and cellular aging, studies evaluating HBO's mutagenic capacity are of fundamental importance, since the therapy is being increasingly used ${ }^{7}$. An easy way to identify in vivo chromosomal aberrations is the micronucleus test, which is considered as the gold standard method for cytogenetic analysis ${ }^{8}$.

The micronucleus (MN), also known as Howell-Jolly corpuscle, is a small chromatin mass, separated from the main cellular nucleus, formed during the telophase in mitosis or meiosis. The MN results from acentric chromosome fragments or from extruding whole chromosomes from the main nucleus ${ }^{9,10}$. When bone marrow erythroblasts expel their nuclei and become erythrocytes, the MN remains in the cytoplasm, where they are identified due to particular characteristics. The young erythrocytes called polychromatic, turn normochromatic (NCE) and get into the bloodstream. The MN can be spontaneously created or induced ${ }^{11}$.

Some studies analyzed HBO mutagenic potential and divergent results were shown ${ }^{12-15}$. Due to the important role in micronucleated cells splenic capture and since little is known about the impact of $\mathrm{HBO}$ on $\mathrm{MN}$ frequency on partially splenectomized animals $^{16}$, we evaluate the mutagenic potential of a HBO protocol by means of a micronucleus test performed in the peripheral blood of Rattus norvegicus Wistar rats submitted to ESTPI, according to techniques already described ${ }^{17-21}$.

\section{Methods}

The present work is an experimental prospective study approved by the Ethics Committee on Animal Use of EMESCAM (protocol number 006/2011).

\section{Sample characteristics and animal handling}

Eighteen male Wistar rats (Rattus Novergicus Albinus, Rodentia, Mammalia), 2-3 months old and weighing about $316 \mathrm{~g}$ were used in the experiment. They were bred at the Research Center at EMESCAM, and kept in suitable and properly identified cages, under appropriate conditions to the species. The animals were divided into three groups with six animals each: group 1 - animals that underwent ESTPI and HBO; group 2 - animals that underwent ESTPI and HBO simulation; group 3 - animals submitted delivery of CP.

\section{Anesthesia and subtotal splenectomy preserving the lower pole}

Groups 1 and 2 were weighed and anesthetized with ketamine at $75 \mathrm{mg} / \mathrm{kg}$ of body weight associated with xylazine at a dose of $5 \mathrm{mg} / \mathrm{kg}$, intraperitoneally delivered. Then the rats were immobilized on a surgical table for performing the thoracic and abdominal wall trichotomy as well as the abdominal wall antisepsis with a $10 \%$ povidone-iodine alcoholic solution.

The surgical procedure ${ }^{2,22}$ consisted of a median longitudinal incision in the skin and in the subcutaneous tissue of about $2.5 \mathrm{~cm}$ long and $0.5 \mathrm{~cm}$ below the xiphoid process. Then, the linea alba and peritoneum were opened. The spleen was mobilized to the surface of the abdominal cavity. The ligation and section of vessels that irrigate the upper and middle portion of the spleen were performed. It was done near to the splenic surface with nylon 6.0. The spleen was sectioned under lacquered vessels and the inferior pole was kept irrigated by gastrosplenic ligament vessels. The raw area of the lower pole was not sutured. The closure of the abdominal cavity was done by continuous suturing the peritoneum and the musculoaponeurotic plan together and followed by the skin using mononylon 6.0 . 
After the surgical procedures, $5 \mathrm{ml}$ of $0.9 \%$ saline were subcutaneously delivered for electrolyte replacement ${ }^{23}$. Analgesia was done by orally dipyrone, dissolved in drinking water at a dose of $52.5 \mathrm{mg} /$ day, for 72 hours, and nalbuphine hydrochloride at a dose of $0.1 \mathrm{mg} / \mathrm{kg}$, subcutaneously delivered every 12 hours, during three days. Food and water ad libitum was offered after surgery.

\section{Oxygen inhalation therapy}

HBO was performed only in group 1, according to the previously established protocol ${ }^{24}$. After the anesthetic effect, animals were placed inside the hyperbaric chamber and subjected to gradual compression of $2.5 \mathrm{~atm}$, with $1 \mathrm{~atm}$ at sea level and $1.5 \mathrm{~atm}$ on the gauge camera for a period of 15 minutes. They were kept under such condition for 90 minutes, followed by exposition to gradual decompression chamber for 15 minutes. This procedure was performed twice a day, with three hours interval between sessions during the first three days and once a day on the following seven days. Group 2 was kept inside the hyperbaric chamber, simulating the same conditions set to the treated animals for identical time applied to group 1. All animals received $4 \mathrm{ml}$ of $0.9 \%$ saline subcutaneously delivered after the $2^{\text {nd }} H B O$ session or simulation in the first three days and after each session or simulation on the following seven days.

\section{Cyclophosphamide delivery}

A single $50 \mathrm{mg} / \mathrm{kg}$ CP dose was administered in animals of group 3, intraperitoneally, according standard protocols ${ }^{25}$. Tail blood samples were taken at the following times: T0 - before CP delivery and T1 - 24 hours after drug delivery.

\section{Micronucleus test in peripheral blood of rats}

Tail blood samples from all rats were collected at the following times: T0 - before surgery (groups 1 and 2) and before CP delivery (group 3); T1 - immediately after the $13^{\text {th }} \mathrm{HBO}$ session or simulation and 24 hours after CP delivery.

Smear was performed from peripheral blood samples, totaling two slides for each animal. They were fixed with methanol PA for ten minutes and after 24 hours they were stained with Leishman, using a modificated Melo's protocol ${ }^{26}$ : the slides were covered with pure Leishman stain for three minutes. They were then covered with Leishman solution in distilled water (1:6) for 15 minutes. Next, the slides were washed five times with pure distilled water.

\section{Animal euthanasia}

Animals from groups 1 and 2 were euthanized immediately after the last HBO session or simulation. Animals from group 3 were euthanized 24 hours after the CP delivery. Anesthesia was performed in order to collect the inferior pole of the spleen; a material that will be used in future studies. The used drugs were ketamine hydrochloride at a dose of $75 \mathrm{mg} / \mathrm{kg}$ of body weight associated with xylazine at a dose of $5 \mathrm{mg} / \mathrm{kg}$, intraperitoneally. Euthanasia was performed with an overdose of sodium pentobarbital at a dose of $120 \mathrm{mg} / \mathrm{kg}$ intraperitoneally, and $10 \%$ potassium chloride, by means of an intracardiac injection (dose effect).

\section{Slides analysis}

The number of MNNCE was determined by the blind counting of $2000 \mathrm{NCE}$ per animal at each time, totaling 24000 cells, per group. The counting was done in an Olympus ${ }^{\circledR}$ optical microscope (100X), under immersion.

\section{Variables and statistical tests}

After cytological analysis of slides containing samples of peripheral blood and checking normal probability distribution (Kolmogorov-Smirnov test), Student's t test for paired samples was used, with a significance level of $p<0.05$, to study the presence or absence of MNNCE and their number in T0 and T1.

\section{Results}

Results are presented on Table 1. No animal had complications or died.

TABLE 1 - Evaluation of micronucleus in animals of groups 1,2 and 3 .

\begin{tabular}{ccccc}
\hline Group & Time & $\begin{array}{c}\text { Arithmetic } \\
\text { mean }\end{array}$ & $\begin{array}{c}\text { Standard } \\
\text { deviation }\end{array}$ & $p$ \\
\hline \multirow{2}{*}{1} & T0 & 0.50 & 0.84 & 0,46 \\
& T1 & 0.17 & 0.41 & \\
\hline \multirow{2}{*}{2} & T0 & 0.33 & 0.52 & 0,17 \\
& T1 & 0.00 & 0.00 & $0,01^{*}$ \\
\hline \multirow{2}{*}{3} & T0 & 2.83 & 1.47 & \multirow{2}{*}{} \\
& T1 & 4.33 & 1.50 & \\
\hline
\end{tabular}




\section{Discussion}

With the purpose of verify the mutagenic effect of HBO treatment, in this study the presence of MN was analyzed in the peripheral blood of Wistar rats submitted to ESTPI followed by $\mathrm{HBO}$ treatment and, the increase of $\mathrm{MN}$ was not observed. Moreover, it was observed that the animals that underwent simulation also did not show increase in the number of $\mathrm{MN}$, which might mean that the stress of this situation by itself is not mutagenic. In the group subjected to the application of $\mathrm{CP}$, there was a significant formation of $\mathrm{MN}$ after 24 hours, demonstrating that it was possible to cause mutations and view them in peripheral blood cells, which is compatible with others studies ${ }^{27,28}$. Another important variable in the micronucleus test is the $\operatorname{sex}^{29-32}$, with males generally being more sensitive to the mutagenic agents than females to the induction of micronuclei ${ }^{33}$. To avoid this problem, we studied only male rats.

Some studies analyzed HBO mutagenic potential and showed no significant $\mathrm{MN}$ increase both in humans ${ }^{12,13}$ and animals ${ }^{14}$. However, divergent results were shown in cell cultures ${ }^{14}$ and human samples ${ }^{15}$. Chromosomal aberrations were found in patients treated with HBO that had comorbidities and used different drugs. This study was conducted in ten sessions, with volunteers that were kept in a hyperbaric chamber with $100 \%$ oxygen at a pressure of 1.5 to $2.0 \mathrm{~atm}$, for 40 minutes, with 15 minutes of compression and decompression ${ }^{15}$. In another study, MN were also observed in cultures of V79 cells from Chinese hamster lung, widely used in genetic toxicology. The significant MN increase was observed after submitting the samples to $98 \%$ oxygen, at a pressure of about 3 atm for three hours. However, at lower exposure time, $\mathrm{MN}$ induction showed no significance ${ }^{14}$.

A new study evaluated the effect genotoxic of HBO in peripheral blood samples from healthy volunteers by using the MN test and the Comet assay, which is another form of cytogenetic analysis. These individuals were treated with $100 \%$ oxygen at $2.5 \mathrm{~atm}$ pressure for three periods of 20 minutes, interspersed with five minutes of breathing room air. The samples were collected immediately, two and 24 hours after the therapy. The MN test did not show chromosomal damage in any of the analyzed periods. However, the Comet assay have detected primary DNA damage immediately after HBO, but not after two and 24 hours. The authors assumed that such result is due to a primary DNA repair mechanism ${ }^{12}$. In a later study, the same group showed that a single HBO session induced adaptive response that protected human blood cells from the genotoxic effects caused by hydrogen peroxide ${ }^{13}$. The great variety of $\mathrm{HBO}$ protocols described may confirm differences in presence of MN founded in many studies.

Reinforcing results from other studies, the current one showed no significant increase in the number of $\mathrm{MN}$ in animals treated with HBO. However, the animals used in this study were submitted to ESTPI, which may have influenced the number of MNNCE found. Since it has been proven that there is an increase in the number of $\mathrm{MN}$ by the use of mutagens in rats submitted to total splenectomy ${ }^{16,34}$, we propose that ESTPI would only partially decrease the splenic capture of these cells. Therefore, it is necessary to develop experiments using $\mathrm{HBO}$ in rats subjected to total and partial splenectomy as well as the preservation of the entire spleen. Studies using mutagens in rats undergoing ESTPI to compare the number of MNNCE in each of these cases are also needed, thus they may allow establishing the most precise way to safely apply the therapy associated with conservative spleen surgery procedures.

\section{Conclusion}

The HBO protocol used in this study did not induce mutagenicity in rats submitted to subtotal splenectomy preserving the lower pole of the spleen. However, specific definitions about the ideal pressure or duration of the HBO sessions were not established.

\section{References}

1. Mortensen CR. Hyperbaric oxygen therapy. Curr Anaesth Crit Care. 2008;19(5-6):333-7.

2. Paulo ICAL, Paulo DNS, Ferrari TA, Azeredo TCV, Silva AL. The splenic inferior pole of rats and hyperbaric oxygen. Rev Assoc Med Bras. 2008 Jan-Feb;54(1):77-81. doi: 10.1590/S010442302008000100025.

3. Paulo MSL, Paulo ICAL, Nunes TA, Silva AL, Cintra LC, Paulo DNS. Effect of hyperbaric oxygen therapy in rats with subtotal splenectomy preserving the inferior pole. Acta Cirur Bras. 2011 Jun;26(3):156-64. doi: 10.1590/S0102-86502011000300002.

4. Paulo MSL, Santos FTB, Rocha PG, Silva MB, Cintra LC, Motta LL, Errera FIV, Paulo DNS, Nunes TA. Immunoexpression of proliferating cell nuclear antigen (PCNA) in spleen of splenectomized rats with preservation of inferior pole, submitted to hyperbaric oxygenation. Acta Cirur Bras. 2013 Oct;28(10):691-5. doi: $10.1590 / \mathrm{S} 0102-86502013001000001$

5. Plafki C, Peters P, Almeling M, Weslau W, Busch, R. Complications and side effects of hyperbaric oxygen therapy. Aviate Space Environ Med. 2000 Feb;71(2):119-24. PMID: 10685584.

6. Dennog C, Hartmann A, Frey G, Speit G. Detection of DNA damage after hyperbaric oxygen (HBO) therapy. Mutagenesis. 1996 Nov;11(6):605-9. PMID: 8962431.

7. Fenech M. The in vitro micronucleus technique. Mutat Res. 2000 Nov;455(1-2):81-95. PMID: 11113469. 
8. Flores M, Yamaguchi MU. Teste do micronúcleo: uma triagem para avaliação genotóxica. Rev Sau Pesq. 2008 Set-Dez;1(3):337-40.

9. Fenech M. The advantages and disadvantages of the cytokinesisblock micronucleus method. Mutat Res. 1997 Aug;392(1-2):11-8. PMID: 9269327.

10. Fenech M, Holland N, Wushou P, Chang WP, Zeiger E, Bonassi $\mathrm{S}$. The human micronucleus project - An international collaborative study on the use of the micronucleus technique for measuring DNA damage in humans. Mutat Res. 1999 Jul;428(1-2):271-83. PMID: 10517999.

11. Schmid W. The micronucleus test. Mutat Res. 1975;31(1):9-15. PMID: 48190.

12. Speit G, Dennog C, Lampl L. Biological significance of DNA damage induced by hyperbaric oxygen. Mutagenesis. 1998 Jan;13(1):85-7. PMID: 9491400.

13. Rothfuss A, Dennog C, Speit G. Adaptive protection against the induction of oxidative DNA damage after hyperbaric oxygen treatment. Carcinogenesis. 1998 Nov;19(11):1913-7. PMID: 9855002.

14. Rothfuss A, Stahl W, Radermacher P, Speit G. Evaluation of mutagenic effects of hyperbaric oxygen (HBO) in vitro. Environ Mol Mutagen. 1999;34(4):291-6. PMID: 10618178.

15. Guskov EP, Shkurat TP, Shimanskaja EI, Guskova SI. Genetic effects of hyperbaric oxygen therapy. Mutat Res. 1990 Aug;241(4):341-7. doi: 10.1016/0165-1218(90)90063-8.

16. Hayashi M, Kodama Y, Awogi T, Suzuki T, Asita AO, Sofuni T. The micronucleus assay using peripheral blood reticolocytes from mitomycin C- and cyclophosphamide-treated rats. Mutat Res. 1992 Feb-Mar;278(2-3):209-13. doi: 10.1016/0165-1218(92)90236-S.

17. Paulo ICAL, Paulo DNS, Cintra LC, Santos MCS, Rodrigues H, Ferrari TA, Azevedo TCV, Silva AL. Preservative spleen surgery and hyperbaric oxygen therapy. Acta Cir Bras. 2007 MarApr;22(1):21-8. PMID: 17505651.

18. Paulo MSL, Paulo ICAL, Nunes TA, Silva AL da, Cintra LC, Paulo DNS. Effect of hyperbaric oxygen therapy in rats with subtotal splenectomy preserving the inferior pole. Acta Cir Bras. 2011 Jun;26(3):156-8. PMID: 21537516.

19. Paulo DNS, Paulo ICAL, Kalil M, Vargas PM, Lázaro da Silva A, Baptista JFA, Guerra AJ. Subtotal splenectomy preserving the lower pole in rats: technical, morphological and functional aspects. Acta Cir Bras. 2006 Sep-Oct;21(5):321-7. PMID: 16981036.

20. Paulo DNS, Ramos BF, Zanetti FR, Marques T, Cintra LC, Paulo ICAL, Silva AL. Growth of the lower spleen pole remaining after subtotal splenectomy in rats. Acta Cir Bras. 2008 MarApr;23(2):125-9. doi: 1590/S0102-86502008000200003.

21. Paulo MSL, Santos FTB, Rocha PG, Silva MB, Cintra LC, Motta LL, Errera FIV, Paulo DNS, Nunes TA. Immunoexpression of proliferating cell nuclear antigen (PCNA) in spleen of splenectomized rats with preservation of inferior pole, submitted to hyperbaric oxygenation. Acta Cir Bras. 2013 Oct;28(10):691-5. doi: 1590/S0102-86502013001000001.

22. Paulo DNS, Silva AL, Cintra LC, Bof AM, Santiago DC, Ribeiro GB. Esplenectomia subtotal, em cães, com preservação do polo inferior suprido por vasos do ligamento gastroesplênico. Rev Col Bras Cir. 1999 Mai-Jun;26(3):147-52. doi: 10.1590/5010069911999000300005.

23. Andersen ML, D'almeida V, Ko GM, Kawakami R, Martins JF, Magalhães LE, Tufik S. Princípios éticos e práticos do uso de animais de experimentação. 1ed. São Paulo: CLR Balieiro Editores; 2004.

24. Paulo DNS, Kalil M, Grillo Junior LSP, Borges EB, Cintra LC, Pereira FEL, Silva AL. Viability of the spleen in rats after ligation of the splenic vessels: effects of hyperbaric oxygen therapy. Rev Assoc
Med Bras. 2005 Jan-Feb;51(1):46-50. PMID: 15776185.

25. Almeida Neto JX, Medeiros FPM, Melo AJM, Silva JC, Dantas JP. Avaliação do efeito mutagênico da palma forrageira (Opuntia ficusindica Mill) através do teste de micronúcleos em medula óssea de ratos (Rattus novergicus, linhagem Wistar) in vivo. Rev Biol Ciênc Ter. 2005;2(5).

26. Melo MEB, Merlo KC, Fernandes RRC, Luna CF, Diniz GTN, Catanho MTJA, Regis L. Mutagenic effects of the organophosphate insecticide temephos on mice bone marrow cells. Rev Inst Adolfo Lutz. 2008 Oct;67(3):196-201.

27. Valshing HL, Kim SK, Feringa ER. Cyclophosphamideinduced abnormalities in the incisors of the rat. J Dent Res. 1977 Jul;56(7):809-16. PMID: 269161.

28. Hamada S, Yamasaki KI, Nakanishi S, Omori T, Serikawa T, Hayashi M. Evaluation of the general suitability of the rat for the micronucleus assay: the effect of cyclophosphamide in 14 strains. Mutat Res. 2001 Aug;495(1-2):127-34. PMID: 11448650.

29. Fenech M, Neville S, Rinaldi J. Sex is an important variable affecting spontaneous micronucleus frequency in cytokinesisblocked lymphocytes. Mutat Res. 1994 Oct-Dec;313(2-3):203-7. PMID: 7523905.

30. Zúñiga-González G, Torres-Bugarín O, Luna-Aguirre J, GonzálezRodríguez A, Zamora-Perez A, Gómez-Meda BC, Ventura-Aguilar AJ, Ramos-Ibarra ML, Ramos-Mora A, Ortíz GG, Gallegos-Arreola MP. Spontaneous micronuclei in peripheral blood erythrocytes from 54 animal species (mammals, reptiles and birds): part two. Mutat Res. 2000 Apr;467(1):99-103. PMID: 10771274.

31. Zuñiga González G, Torres-Bugarín O, Ramos-Ibarra ML, ZamoraPerez A, Gómez-Meda BC, Ventura-Aguilar A, Ramos-Mora A, Ortíz GG, Alvarez-Moya C, González-Rodrígruez A, LunaAguirre J, Gallegos-Arreola MP. Variation of micronucleated erytrocytes in peripheral blood of Sciurius aureogaster in relation to age: an increment of micronucleated polychromatic erythrocytes after the administration of colchicine. Environ Mol Mutagen. 2001;37(2):173-7. PMID: 11246224.

32. Zuñiga González G, Torres-Bugarín O, Zamora-Pérez A, GómezMeda BC, Ramos Ibarra ML, Martínez-González S, GonzálezRodríguez A, Luna-Aguirre J, Ramos-Mora A, Ontiveros-Lira D, Gallegos-Arreola MP. Differences in the number of micronucleated erythrocytes among young and adult animals including humans. Spontaneous micronuclei in 43 species. Mutat Res. 2001 Jul;494(12):161-7. PMID: 11423355.

33. Hayashi M, Sofuni T, Ishidate M. High-sensitivity in micronucleus induction of a mouse strain (MS). Mutat Res.1982 Oct;105(4):2536. PMID: 7133031.

34. Schlegel R, Macgragor JT. The persistence of micronucleated erythrocytes in the peripheral circulation of normal and splenectomized Fischer 344 rats: implications for cytogenetic screening. Mutat Res. 1984 Jul;127(2):169-74. PMID: 6749161.

\section{Acknowledgements}

To Luiz Antônio de Oliveira, Roberta Miranda de Araújo Mendes and Marcos Vinícius Gumiero for their technical support during the development of the study in the Laboratory of Animal Experimentation (EMESCAM) and the Oncology and Hematology Medical Services for drug donation for research. 


\section{Correspondence:}

Flávia Imbroisi Valle Errera

Rua Aquino Araújo, 77/1102

29101-240 Vila Velha - ES Brasil

Tel.: (55 27)3340-1353/99919-5218

flavia.errera@emescam.br

Received: Dec 18, 2014

Review: Feb 21, 2015

Accepted: Mar 19, 2015

Conflict of interest: none

Financial sources: Foundation for Research Support of the State of Espírito Santo (FAPES) and Institute for Sustained Development and Practical Actions in the Area of Health (Instituto Solidario)

${ }^{1}$ Research performed at Laboratories of Animal Experimentation and Genetics, ICALP Research Center, College of Health Sciences, EMESCAM, Vitoria-ES, Brazil. 